Journal of Mathematics and Statistics 5 (3):178-182, 2009

ISSN 1549-3644

(C) 2009 Science Publications

\title{
Hypercyclic Functions for Backward and Bilateral Shift Operators
}

\author{
${ }^{1}$ N. Faried, ${ }^{2}$ Z.A. Hassanain and ${ }^{3}$ A. Morsy \\ ${ }^{1}$ Department of Mathematics, \\ Faculty of Science, Ain Shams University, Cairo, Egypt \\ ${ }^{2}$ Department of Mathematics, \\ Higher Technological Institute, 10th of Ramadan City, Egypt \\ ${ }^{3}$ Department of Mathematics, Faculty of Engineering, \\ The British University in Egypt, El Sherouk City, Egypt
}

\begin{abstract}
Problem statement: Giving conditions for bilateral forward and unilateral backward shift operators over the weighted space of p-summable formal series to be hypercyclic. This provides a generalization to the case of Hilbert space. Approach: We used hypercyclicity criterion and some preliminary concepts for formal Laurent series and formal power series. Moreover we got benefits of some duality properties of above mentioned spaces. Results: We obtained necessary and sufficient conditions for bilateral forward and unilateral backward shift operators to be hypercyclic. Conclusion: The bilateral forward shift operator was hypercyclic on the space of all formal Laurent series and the unilateral backward shift operator was hypercyclic on the space of all formal power series under certain conditions.
\end{abstract}

Key words: Bilateral shift operators, weighted shift operators, hypercyclic functions, hypercyclic operators

\section{INTRODUCTION}

A vector $\mathrm{x}$ in a Banach space $\mathrm{X}$ is called hypercyclic for a bounded operator $\mathrm{T}$ if the orbit $\left\{T^{n} x: n \geq 0\right\}$ is dense in $X$. The first examples of hypercyclic operators appeared in the space of entire functions defined over the complex plane, endowed with the compact-open topology. In 1929 Birkhoff $^{[1]}$ essentially showed the hypercyclicity of the translation operators $\mathrm{T}_{\mathrm{a}} \mathrm{f}(\mathrm{z})=\mathrm{f}(\mathrm{z}+\mathrm{a}), \mathrm{a} \neq 0$, while MacLane $^{[2]}$ proved the hypercyclicity of the differentiation operator. The notion of hypercyclicity on Banach spaces started in 1969 with Rolewicz ${ }^{[3]}$, who showed that any scalar multiple $\lambda \mathrm{B}$ of the unilateral backward shift $B$ is hypercyclic on $1^{\mathrm{p}}(1 \leq \mathrm{p}<\infty)$ and $\mathrm{c}_{0}$, whenever $|\lambda|>1$. Kitai in his thesis with title invariant closed sets for linear operators, university of Toronto, determined conditions under which a linear operator is hypercyclic. This result, commonly referred to as the hypercyclicity criterion, was never published and a few years later it was rediscovered in a broader form by Gethner and Shapiro ${ }^{[5]}$. During the last year's hypercyclicity criterion on Banach or Frechet spaces has attracted many mathematicians working in linear functional analysis and very important contributions to the topic have been made ${ }^{[5-13]}$.

We use the hypercyclicity criterion of ${ }^{[10]} \mathrm{G}$. Godefroy and J. H. Shapiro (1991), to show that the bilateral forward shift operators on the space of all formal Laurent series and the unilateral backward shift operators on the space of all formal power series are hypercyclic. Our results in the case $p=2$ are compatible to that given by H. Salas (1995) on the space $\mathrm{l}^{2}(\mathrm{Z})$ and generalize those given by ${ }^{[12]}$.

\section{MATERIALS AND METHODS}

Let $\{\beta(\mathrm{k})\}$ be a sequence of positive numbers with $\beta(0)=1$. We consider the space of all functions $f(z)=\sum_{k} a_{k} \frac{z^{k}}{\beta(k)}$ such that:

$\|\mathrm{f}\|=\left(\sum_{\mathrm{k}}\left|\mathrm{a}_{\mathrm{k}}\right|^{\mathrm{P}}\right)^{\frac{1}{\mathrm{P}}}<\infty$

if $\mathrm{k}$ ranges only the nonnegative integers, these are formal power series, otherwise they are formal Laurent 
series, where $\frac{z^{k}}{\beta(k)}$ is an orthonormal basis. We shall denote these spaces by:

$\mathrm{H}_{\beta}^{\mathrm{p}}$ : Power series case

$\mathrm{E}_{\beta}^{\mathrm{p}}$ : Laurent series case

Definition: The operator $M_{z}$ on $E_{\beta}^{p}$ defined by $\mathrm{M}_{\mathrm{z}} \mathrm{f}(\mathrm{z})=\mathrm{zf}(\mathrm{z})$ is called the bilateral forward shift; furthermore, the inverse of $\mathrm{M}_{\mathrm{z}}$ which is the bilateral backward shift is the operator $B_{z}$ defined on $E_{\beta}^{P}$ by $B_{z} f(z)=\frac{f(z)}{z}$. The right inverse of $M_{z}$ is the unilateral backward shift operator $\mathrm{S}_{\mathrm{z}}$ defined on $\mathrm{H}_{\beta}^{\mathrm{p}}$ by,

$$
S_{\mathrm{z}} \mathrm{f}(\mathrm{z})=\frac{\mathrm{f}(\mathrm{z})-\mathrm{f}(0)}{\mathrm{z}}
$$

Noting that the shift operator defined over the space $E_{\beta}^{p}$ by $R_{z} f(z)=\sum_{k} a_{k} \frac{z^{k+1}}{\beta(k+1)}$ is a shift operator, for which $\left\|\mathrm{R}_{\mathrm{z}}\right\|=1$.

Since $\beta(\mathrm{k})>0, \forall \mathrm{k} \in \mathrm{Z}$, then by taking $\mathrm{w}_{\mathrm{k}}=\frac{\beta(\mathrm{k}+1)}{\beta(\mathrm{k})}$ we get $\beta(n)=\prod_{k=0}^{n-1} w_{k}$ and $\beta(n)=\prod_{k=0}^{n-1}\left(w_{-k}\right)^{-1} \forall n \in N$ and the operator $\mathrm{T}$ defined by $\mathrm{Te}_{\mathrm{k}}=\mathrm{w}_{\mathrm{k}} \mathrm{e}_{\mathrm{k}+1}$ is an injective bilateral forward weighted shift operator on $I^{p}(Z)=\left\{x: x=\sum_{k \in Z} x_{k} e_{k},\|x\|^{p}=\sum_{k \in Z}\left|x_{k}\right|^{p}<\infty\right\} \quad$ with weight sequence $\left\{\mathrm{w}_{\mathrm{k}}\right\}_{\mathrm{k}=-\infty}^{\infty}, \mathrm{w}_{\mathrm{k}} \neq 0$. On the other hand the operator $\mathrm{V}$ defined by $\mathrm{Ve}_{\mathrm{k}}=\frac{1}{\mathrm{w}_{\mathrm{k}-1}} \mathrm{e}_{\mathrm{k}-1}$ is an injective backward weighted shift operator on $\mathrm{l}^{\mathrm{p}}(\mathrm{Z})$ with weight sequence $\left\{w_{k}\right\}_{k=-\infty}^{\infty}, w_{k} \neq 0$.

Proposition 1: The bilateral forward shift operator $\mathrm{M}_{z}$ on $\mathrm{E}_{\beta}^{\mathrm{p}}$ is unitarily equivalent to the injective bilateral forward weighted shift operator $\mathrm{T}$ mentioned above. Conversely, every injective bilateral forward weighted shift operator T is unitarily equivalent to $M_{z}$ acting on $E_{\beta}^{p}$.

Proof: We define the unitary operator $U: 1^{\mathrm{P}}(\mathrm{Z}) \rightarrow \mathrm{E}_{\beta}^{\mathrm{P}}$ by:

$$
\mathrm{Ue}_{\mathrm{k}}:=\frac{\mathrm{z}^{\mathrm{k}}}{\beta(\mathrm{k})}
$$

Hence:

$$
\mathrm{U}^{*} \frac{\mathrm{z}^{\mathrm{k}}}{\beta(\mathrm{k})}=\mathrm{e}_{\mathrm{k}}
$$

Then:

$$
\mathrm{U}^{*} \mathrm{M}_{\mathrm{z}} \mathrm{Ue}_{\mathrm{k}}=\mathrm{w}_{\mathrm{k}} \mathrm{e}_{\mathrm{k}+1}
$$

So, $M_{z}$ is unitarily equivalent to an injective bilateral forward weighted shift operator (with the weight sequence $\left.\left\{\mathrm{w}_{\mathrm{k}}\right\}\right)$.

Conversely, since $\mathrm{T}$ is injective bilateral forward weighted shift with weight $w_{n}$, then $\beta(n) \neq 0$ for all $n$. Without loss of generality ${ }^{[4]}$, we may assume that the shifts have positive weights $\beta(n)$. Noting that:

$$
\mathrm{TU}^{*} \frac{\mathrm{z}^{\mathrm{k}}}{\beta(\mathrm{k})}=\mathrm{w}_{\mathrm{k}} \mathrm{e}_{\mathrm{k}+1}
$$

We get:

$$
\mathrm{UTU}^{*}=\mathrm{M}_{\mathrm{z}}
$$

Proposition 2: The bilateral backward shift operator $\mathrm{B}_{z}$ on $\mathrm{E}_{\beta}^{\mathrm{p}}$ is unitarily equivalent to the injective weighted shift linear operator $\mathrm{V}$ mentioned above (with the weight sequence $\left.\left\{\left(\mathrm{w}_{\mathrm{k}-1}\right)^{-1}\right\}\right)$. Conversely, every injective weighted shift operator is unitarily equivalent to $B_{z}$ acting on $E_{\beta}^{p}$.

The proof of this result is similar to that of proposition 1 .

Proposition 3: The powers $M_{z}^{n}$ of the operator $M_{z}$ are bounded on $E_{\beta}^{p}$ with $\left\|M_{z}^{n}\right\|=\sup _{k} \frac{\beta(k+n)}{\beta(k)}$ provided that the supremum in the right hand side exists.

Proof: For $f \in E_{\beta}^{p}$, it is seen that $M_{z}^{n} f(z)=\sum_{k=-\infty}^{\infty} a_{k} \frac{z^{k+n}}{\beta(k)}$ and hence:

$$
\left\|M_{z}^{n} f\right\|=\left(\sum_{k=-\infty}^{\infty}\left|a_{k}\right|^{\mathrm{P}}\left(\frac{\beta(\mathrm{k}+\mathrm{n})}{\beta(\mathrm{k})}\right)^{\mathrm{P}}\right)^{1 / \mathrm{P}} \leq \sup _{\mathrm{k}} \frac{\beta(\mathrm{k}+\mathrm{n})}{\beta(\mathrm{k})}\|\mathrm{f}\|
$$

Thus: 


$$
\left\|\mathbf{M}_{\mathrm{z}}^{\mathrm{n}}\right\| \leq \sup _{\mathrm{k}} \frac{\beta(\mathrm{k}+\mathrm{n})}{\beta(\mathrm{k})}
$$

On the other hand $\left\|\frac{z^{\mathrm{k}+\mathrm{n}}}{\beta(\mathrm{k})}\right\| \leq\left\|\mathrm{M}_{\mathrm{z}}^{\mathrm{n}}\right\| \quad$ and so $\frac{\beta(\mathrm{k}+\mathrm{n})}{\beta(\mathrm{k})} \leq\left\|\mathrm{M}_{\mathrm{z}}^{\mathrm{n}}\right\| ;$ hence $\sup _{\mathrm{k}} \frac{\beta(\mathrm{k}+\mathrm{n})}{\beta(\mathrm{k})} \leq\left\|\mathrm{M}_{\mathrm{z}}^{\mathrm{n}}\right\|$ and the result holds.

In the same manner we can prove that $\left\|B_{z}^{n}\right\|=\sup _{k} \frac{\beta(k-n)}{\beta(k)}$ and $\left\|S_{z}^{n}\right\|=\sup _{k} \frac{\beta(k)}{\beta(k+n)}$ provided that the right hand side exists in each case.

Proposition 4: A sufficient condition for the series $\sum_{\mathrm{k}=-\infty}^{\infty} \mathrm{a}_{\mathrm{k}} \frac{\mathrm{z}^{\mathrm{k}}}{\beta(\mathrm{k})}$ to be convergent is:

$\lim _{k \rightarrow \infty} \sup _{k} \frac{1}{(\beta(-k))^{1 / k}}<|z|<\liminf _{k \rightarrow \infty}(\beta(k))^{1 / k}$

Proof: Let $f(z)=\sum_{k=-\infty}^{\infty} a_{k} \frac{z^{k}}{\beta(k)} \in E_{\beta}^{P}$. Since condition (2) is sufficient for the convergence of the series $\sum_{\mathrm{k}} \frac{|\mathrm{z}|^{\mathrm{kq}}}{\beta^{\mathrm{q}}(\mathrm{k})}$ for every $z$, then by using Hölder inequality we get:

$$
|f(z)|=\left|\sum_{k} a_{k} \frac{z^{k}}{\beta(k)}\right| \leq\left(\sum_{k}\left|a_{k}\right|^{p}\right)^{1 / p}\left(\sum_{k} \frac{|z|^{k q}}{\beta^{q}(k)}\right)^{1 / q}
$$

This is the required result.

One can easily see that the dual of $\mathrm{E}_{\beta}^{\mathrm{p}}$ is $\mathrm{E}_{\gamma}^{\mathrm{q}}$, where $\frac{1}{\mathrm{p}}+\frac{1}{\mathrm{q}}=1$ and $\gamma=\{\gamma(\mathrm{k})\}=\left\{(\beta(\mathrm{k}))^{-1}\right\}$. In fact, for any functional $U$ on $E_{\beta}^{p}$, there exist an element $\mathrm{g}(\mathrm{z})=\sum_{\mathrm{k}} \mathrm{b}_{\mathrm{k}} \frac{\mathrm{z}^{\mathrm{k}}}{\gamma(\mathrm{k})} \in \mathrm{E}_{\gamma}^{\mathrm{q}}$ such that

$\mathrm{U}(\mathrm{f}(\mathrm{z}))=\langle\mathrm{f}(\mathrm{z}), \mathrm{g}(\mathrm{z})\rangle=\sum_{\mathrm{k}} \mathrm{a}_{\mathrm{k}} \mathrm{b}_{\mathrm{k}} \quad$ for $\quad \operatorname{any} \mathrm{f}(\mathrm{z})=\sum_{\mathrm{k}} \mathrm{a}_{\mathrm{k}} \frac{\mathrm{z}^{\mathrm{k}}}{\beta(\mathrm{k})}$, where $\langle f(z), g(z)\rangle$ denote the value of the functional $\mathrm{g}(\mathrm{z}) \in \mathrm{E}_{\gamma}^{\mathrm{q}}$ on the element $\mathrm{f}(\mathrm{z}) \in \mathrm{E}_{\beta}^{\mathrm{p}}$. According to this notation we get:

$$
\left\langle\frac{\mathrm{z}^{\mathrm{k}}}{\beta(\mathrm{k})}, \frac{\mathrm{z}^{\mathrm{m}}}{\gamma(\mathrm{m})}\right\rangle=\delta_{\mathrm{k}, \mathrm{m}}
$$

\section{RESULTS}

Now we give necessary and sufficient conditions for bilateral forward shift operator on the space $E_{\beta}^{p}$ is hypercyclic.

Proposition 5: The bilateral forward shift operator $\mathrm{M}_{\mathrm{z}}$ on $\mathrm{E}_{\beta}^{\mathrm{p}}$ is hypercyclic if and only if for every $\varepsilon>0$ and $q \in N$, there exists sufficiently large $n_{i} \in N$, such that for every $|\mathrm{k}| \leq \mathrm{q}$ :

$\frac{\beta\left(\mathrm{k}+\mathrm{n}_{\mathrm{i}}\right)}{\beta(\mathrm{k})}<\varepsilon$ and $\frac{\beta(\mathrm{k})}{\beta\left(\mathrm{k}-\mathrm{n}_{\mathrm{i}}\right)}>\frac{1}{\varepsilon}$

Proof: Assume that $M_{z}$ is hypercyclic. Since the set of hypercyclic functions for $\mathrm{M}_{\mathrm{z}}$ is dense, then given $\varepsilon>0$ and $\mathrm{q} \in \mathrm{N}$, let $0<\delta<1$ so that $0<\delta /(1-\delta)<\varepsilon$ and there is a hypercyclic function $f(z)$ for $M_{z}$ such that:

$$
\left\|f(z)-\sum_{|k| \leq q} \frac{z^{k}}{\beta(k)}\right\|<\delta
$$

Using the functionals $\frac{\mathrm{z}^{\mathrm{m}}}{\gamma(\mathrm{m})}$ with norm one in the dual space of $E_{\beta}^{p}$ such that:

$$
\left|\left\langle\mathrm{f}(\mathrm{z})-\sum_{|\mathrm{k}| \leq \mathrm{q}} \frac{\mathrm{z}^{\mathrm{k}}}{\beta(\mathrm{k})}, \frac{\mathrm{z}^{\mathrm{k}}}{\gamma(\mathrm{k})}\right\rangle\right| \leq\left\|\mathrm{f}(\mathrm{z})-\sum_{|\mathrm{k}| \leq \mathrm{q}} \frac{\mathrm{z}^{\mathrm{k}}}{\beta(\mathrm{k})}\right\|<\delta
$$

We get:

$\left|\mathrm{a}_{\mathrm{k}}\right|<\delta, \quad \quad|\mathrm{k}|>\mathrm{q}$

$\left|\mathrm{a}_{\mathrm{k}}\right|>1-\delta, \quad|\mathrm{k}| \leq \mathrm{q}$

Since $f(z)$ is hypercyclic, we can choose $n_{i}>2 q$ such that:

$\left\|\mathrm{M}_{\mathrm{z}}^{\mathrm{n}_{\mathrm{i}}} \mathrm{f}(\mathrm{z})-\sum_{|\mathrm{k}| \leq \mathrm{q}} \frac{\mathrm{z}^{\mathrm{k}}}{\beta(\mathrm{k})}\right\|<\delta$

Let $|\mathrm{k}| \leq \mathrm{q}$ be fixed. Since $\mathrm{n}_{\mathrm{i}}>2 \mathrm{q}$ inequality (6) implies that:

$$
\left\|\left\langle\mathrm{M}_{\mathrm{z}}^{\mathrm{n}_{\mathrm{i}}} \mathrm{f}(\mathrm{z})-\sum_{|\mathrm{k}| \leq \mathrm{q}} \frac{\mathrm{z}^{\mathrm{k}}}{\beta(\mathrm{k})}, \frac{\mathrm{z}^{\mathrm{k}+\mathrm{n}_{\mathrm{i}}}}{\gamma\left(\mathrm{k}+\mathrm{n}_{\mathrm{i}}\right)}\right\rangle\right\|=\frac{\beta\left(\mathrm{k}+\mathrm{n}_{\mathrm{i}}\right)}{\beta(\mathrm{k})}\left|\mathrm{a}_{\mathrm{k}}\right|<\delta
$$


From (4) and (5) we get:

$$
\frac{\beta\left(\mathrm{k}+\mathrm{n}_{\mathrm{i}}\right)}{\beta(\mathrm{k})}<\frac{\delta}{1-\delta}<\varepsilon
$$

On the other hand, inequality (6) implies that:

$$
\|\left\langle\mathrm{M}_{\mathrm{z}}^{\mathrm{n}_{\mathrm{i}}} \mathrm{f}(\mathrm{z})-\sum_{|\mathrm{k}| \leq \mathrm{q}} \frac{\mathrm{z}^{\mathrm{k}}}{\beta(\mathrm{k})}, \frac{\mathrm{z}^{\mathrm{k}}}{\gamma(\mathrm{k})}\right\rangle|=| \mathrm{a}_{\mathrm{k}-\mathrm{n}_{\mathrm{i}}} \frac{\beta(\mathrm{k})}{\beta\left(\mathrm{k}-\mathrm{n}_{\mathrm{i}}\right)}-1 \mid<\delta
$$

Therefore:

$$
\frac{\beta(\mathrm{k})}{\beta\left(\mathrm{k}-\mathrm{n}_{\mathrm{i}}\right)}>\frac{1-\delta}{\mathrm{a}_{\mathrm{k}-\mathrm{n}_{\mathrm{i}}}}>\frac{1-\delta}{\delta}>\frac{1}{\varepsilon}
$$

Conversely, let $Y_{0}:=\operatorname{span}\left\{\frac{\mathrm{z}^{\mathrm{k}}}{\beta(\mathrm{k})}, \mathrm{k} \in \mathrm{Z}\right\}$ be a dense subset of $E_{\beta}^{p}$ and let $B_{z}: Y_{0} \rightarrow Y_{0}$ be the linear mapping defined by:

$\mathrm{B}_{\mathrm{z}}\left(\frac{\mathrm{z}^{\mathrm{k}}}{\beta(\mathrm{k})}\right):=\frac{\mathrm{z}^{\mathrm{k}-1}}{\beta(\mathrm{k})}$

Notice that $B_{z} M_{z}=M_{z} B_{z}=I d_{Y_{0}}$. It is easy to see that $\mathrm{M}_{\mathrm{z}}^{\mathrm{n}_{\mathrm{i}}} \rightarrow 0$ point-wisely on $\mathrm{Y}_{0}$. On the other hand by using (3) we get:

$$
\left\|\mathrm{B}_{\mathrm{z}}^{\mathrm{n}_{\mathrm{i}}} \sum_{\mathrm{k}} \mathrm{a}_{\mathrm{k}}\left(\frac{\mathrm{z}^{\mathrm{k}}}{\beta(\mathrm{k})}\right)\right\|^{\mathrm{p}}=\sum_{\mathrm{k}}\left|\mathrm{a}_{\mathrm{k}}\right|^{\mathrm{P}}\left(\frac{\beta\left(\mathrm{k}-\mathrm{n}_{\mathrm{i}}\right)}{\beta(\mathrm{k})}\right)^{\mathrm{P}} \underset{\mathrm{i} \rightarrow \infty}{\longrightarrow} 0
$$

Thus the hypercyclicity criterion is satisfied and the proof is complete.

\section{DISCUSSION}

Results obtained from proposition 5 can be applied in the next proposition but for the unilateral backward shift operator on the space $\mathrm{H}_{\beta}^{\mathrm{p}}$.

Proposition 6: The unilateral backward inverse shift operator $\mathrm{S}_{\mathrm{z}}$ on $\mathrm{H}_{\beta}^{\mathrm{p}}$ is hypercyclic if and only if for every $\varepsilon>0$ and $q \in N$, there exists sufficiently large $n_{i} \in N$, such that for every $\mathrm{k} \in \mathrm{N}$ :

$$
\frac{\beta\left(\mathrm{k}+\mathrm{n}_{\mathrm{i}}\right)}{\beta(\mathrm{k})}<\varepsilon
$$

Proof: Assume that $S_{z}$ is hypercyclic. Since the set of hypercyclic functions for $S_{z}$ is dense, then given $\varepsilon>0$ and $\mathrm{q} \in \mathrm{N}$, let $0<\delta<1$ so that $0<\delta /(1-\delta)<\varepsilon$ and there is a hypercyclic function $f(z)$ for $S_{z}$ such that:

$$
\left\|f(z)-\sum_{k=0}^{q} \frac{z^{k}}{\beta(k)}\right\|<\delta
$$

Choosing suitable functionals in the dual space of $\mathrm{E}_{\beta}^{\mathrm{p}}$ we get:

$$
\begin{array}{cc}
\left|\mathrm{a}_{\mathrm{k}}\right|<\delta, & \mathrm{k}>\mathrm{q} \\
\left|\mathrm{a}_{\mathrm{k}}\right|>1-\delta, & 0 \leq \mathrm{k} \leq \mathrm{q}
\end{array}
$$

Since $f(z)$ is hypercyclic, we can choose $n_{i}>q$ such that:

$\left\|\mathrm{S}_{\mathrm{z}}^{\mathrm{n}_{\mathrm{i}}} \mathrm{f}(\mathrm{z})-\sum_{\mathrm{k}=0}^{\mathrm{q}} \frac{\mathrm{z}^{\mathrm{k}}}{\beta(\mathrm{k})}\right\|<\delta$

Let $0 \leq \mathrm{k} \leq \mathrm{q}$ be fixed. From (9), (10) and (11) we get:

$$
1-\delta<\left|\mathrm{a}_{\mathrm{k}+\mathrm{n}_{\mathrm{i}}}\right| \frac{\beta(\mathrm{k})}{\beta\left(\mathrm{k}+\mathrm{n}_{\mathrm{i}}\right)}<\delta \frac{\beta(\mathrm{k})}{\beta\left(\mathrm{k}+\mathrm{n}_{\mathrm{i}}\right)}
$$

Therefore:

$$
\frac{\beta\left(\mathrm{k}+\mathrm{n}_{\mathrm{i}}\right)}{\beta(\mathrm{k})}<\frac{\delta}{1-\delta}<\varepsilon
$$

Conversely let $X_{0}:=\operatorname{span}\left\{\frac{\mathrm{z}}{\beta(1)}, \frac{\mathrm{z}^{2}}{\beta(2)}, \ldots ..\right\}$ be a dense subset of $H_{\beta}^{p}$ and let $A_{z}: X_{0} \rightarrow X_{0}$ be the linear mapping defined by:

$A_{z}\left(\frac{z^{k}}{\beta(k)}\right):=\frac{z^{k+1}}{\beta(k)}$

Notice that $\left(\mathrm{S}_{\mathrm{z}} \mathrm{A}_{\mathrm{z}}\right) \mathrm{f}(\mathrm{z})=\mathrm{f}(\mathrm{z})$ and $\mathrm{S}_{\mathrm{z}}^{\mathrm{n}_{\mathrm{i}}} \rightarrow 0$ pointwisely on $\mathrm{X}_{0}$. On the other hand by using (8) we get:

$$
\left\|A_{z}^{n_{i}} \sum_{k=0}^{\infty} a_{k}\left(\frac{z^{k}}{\beta(k)}\right)\right\|^{p}=\sum_{k=0}^{\infty}\left|a_{k}\right|^{P}\left(\frac{\beta\left(k+n_{i}\right)}{\beta(k)}\right)^{P} \underset{i \rightarrow \infty}{\longrightarrow} 0
$$


Thus the hypercyclicity criterion is satisfied and the proof is complete.

\section{CONCLUSION}

The bilateral forward shift operator is hypercyclic on the space of all formal Laurent series and the unilateral backward shift operator is hypercyclic on the space of all formal power series under certain conditions. Propositions 5 and 6 in the case of $p=2$ are compatible with that given in ${ }^{[7]}$ over the space $1^{2}(Z)$ and in ${ }^{[10]}$ over the space $1^{2}(N)$. Noting that, some examples of hypercyclic bounded linear operators have applications in physics and quantum radiation field theory ${ }^{[10,12]}$.

\section{REFERENCES}

1. Birkhoff, G.D., 1929. Demonstration due theoreme elementaire sur les functions entieres. C. R. Acad. Sci. Paris, 189: 473-475. http://www.emis.de/cgibin/JFM-item?55.0192.07

2. MacLane, G.R., 1952. Sequences of derivatives and normal families. J. Anal. Math., 2: 72-87. DOI: 10.1007/BF02786968

3. Rolewicz, S., 1969. On orbits of elements. Studia Math., 32: 17-22. journals.impan.gov.pl/cgibin/shvold?sm32

4. Douglas, R.G., H.S. Shapiro and A.L. Shields, 1970. Cyclic vectors and invariant subspaces for the backward shift operator. Ann. de 1, Inst. Fourier, 20: 37-76. http://www.numdam.org/item?id=AIF_1970_20_ 1_37_0
5. Gethner, R.M. and J.H. Shapiro, 1987. Universal vectors for operators on spaces of holomorphic functions. Proc. Am. Math. Soc., 100: 281-288. http://www.jstor.org/stable/2045959

6. Bourdon, P.S., 1993. Invariant manifolds of hypercyclic vectors. Proc. Am. Math. Soc., 118: 845-847. http://www.jstor.org/stable/2160131

7. Salas, H., 1995. Hypercyclic weighted shifts. Proc. Am. Soc., 347: 993-1004. http://www.jstor.org/stable/2154883

8. Ansari, S.I., 1995. Hypercyclic and cyclic vectors. J. Funct. Anal., 128: 374-383. DOI: 10.1006/JFAN.1995.1036

9. Salas, H.N., 1999. Supercyclicity and weighted shifts. Studia Math., 135: 55-74. http://matwbn.icm.edu.pl/ksiazki/sm/sm135/sm135 15.pdf

10. Juan Bes and Alfedo peris, 1999. Hereditarily hypercyclic operators. J. Funct. Anal., 167: 94-112. DOI: 10.1006/JFAN.1999.3437

11. Rodriguez, A.M. and H.N. Salas, 2001. Supercyclic subspace: Spectral theory and weighted shifts. Adv. Math., 163: 74-134. DOI: 10.1006/AIMA.2001.2001

12. Emamirad, H. and G.S. Heshmati, 2005. Chaotic weighted shifts in Bargmann space. J. Math. Anal. App., 100: 36-46. DOI: 10.1016/J.JMAA.2004.10.035

13. Salas, H., 2006. Pathological hypercyclic operators. Arch. Math., 86: 241-250. DOI: $10.1007 / \mathrm{s} 00013-005-1511-\mathrm{y}$ 